IP Periodica Polytechnica

Mechanical Engineering

60(2), pp. 82-88, 2016

DOI: $10.3311 /$ PPme. 8564

Creative Commons Attribution (i)

RESEARCH ARTICLE

\section{Evaporation of Renewable Fuels in a Lean Premixed Prevaporized Burner}

\author{
Viktor Józsa $^{1 *}$, Dávid Csemány ${ }^{1}$
}

Received 21 September 2015; accepted after revision 08 January 2016

\begin{abstract}
The last decades have emphasized the requirement for alternative energy sources, particularly in the transport sector, where combustible liquid fuels are expected to dominate in the foreseeable future. In such applications, the fuel must be efficiently atomized, evaporated, and mixed with the combustion air before it reaches the flame front, in order to meet the latest pollutant emission standards.

Hence, this paper investigates the utilization of nine different fossil and renewable liquid fuels. The domain of the analysis is a lean premixed prevaporized burner equipped with an air blast atomizer and a mixing tube. Analytical calculations are performed to determine the evaporation process after the atomization; then the evaporation time is compared to the residence time of the droplets in the mixing tube. The effect of preheating both the fuel and the combustion air is also examined to determine proper combustion conditions even for the low volatile crude vegetable oils.
\end{abstract}

\section{Keywords}

lean premixed prevaporized, air blast atomization, evaporation, renewable fuel

\footnotetext{
${ }^{1}$ Department of Energy Engineering, Faculty of Mechanical Engineering, Budapest University of Technology and Economics

H-1111 Budapest, Mủegyetem rkp. 3., Hungary

${ }^{*}$ Corresponding author, e-mail: jozsa@energia.bme.hu
}

\section{Introduction}

In the $20^{\text {th }}$ century, a major achievement of combustion research was to develop highly efficient combustion systems [1]. Furthermore, fossil fuels have to be replaced with renewables, in order to reach sustainable economy. The challenge of the $21^{\text {st }}$ century is to find the best ratio of crop usage between food and biofuel [2]. Due to the lack of viable alternative solution, combustible liquid fuels seems to dominate the transportation sector particularly in the foreseeable future [3].

Globally, standards force the oil companies to add fatty acid methyl esters (FAMEs) to the diesel fuel. In the European Union, the EN 590 diesel oil standard allows maximum 7\% FAME content by volume. It is fulfilled especially by adding rapeseed methyl ester (RME). In parallel, transesterified soybean oil is the typical diesel oil additive in the US. The scope of the current paper is to compare the atomization and evaporation characteristics of popular renewable liquid fuels with fossil ones. These are ethanol, n-heptane, diesel oil (according to EN 590), RME, and the following crude vegetable oils: jatropha, palm, rapeseed, soybean, and sunflower.

To date, the attention is focused on the possibilities of direct utilization of crude vegetable oils in our current heat engines. Furthermore, setting development goals is of primary importance. Therefore, the aim of the present paper is to evaluate the interchangeability of diesel oil to crude vegetable oils in an atmospheric burner. However, there are high-pressure applications, (e.g., gas turbines, internal combustion engines, highpressure furnaces) the most crucial part of their operation is the startup process [4]. Therefore, the atmospheric back pressure is used at the burner tip. It is out of the question that the most likely advancement towards clean combustion is to increase the ratio of renewables in the utilized fuel [3]. Despite that, the worst-case scenario is to be investigated from combustion point of view, namely, utilizing pure renewable fuels. Of course, by blending, the situation is always better [5].

Historically, the air blast atomizer was developed by Lefebvre [6], which is capable of operating even at full load and idle fuel flow rates (i.e. this ratio is 50:1 in aero propulsion gas turbines). Furthermore, the mentioned class of atomizers is widely used in 
other fields, such as metallurgy for powder production [7], painting, and coating technologies [8]. A previous study has revealed that the pollutant emissions have a minimum at the critical atomizing pressure ratio [9]. Consequently, it was chosen as an upper limit of the current investigation. Hence, the flow field can be handled in an easier way, while it is free from shock waves.

Following the atomization, the droplets travel towards the flame front, evaporate and mix with the combustion air in an ideal case. If only a mentioned process is inadequate, the flame can become uneven, and the appearing hot spots decrease the maintenance intervals and increase the emission of nitrogen oxides. Furthermore, the worst possible consequent event is the combustion instability or even engine failure [10-12].

To overcome such problems, the lean premixed prevaporized (LPP) burners were developed, which configuration is investigated in this paper. It features a mixing tube, where the combustion air and the evaporated fuel can mix.

\section{The investigated burner}

Figure 1 shows the investigated LPP burner with the dimensions of the mixing tube that is of primary interest in the present paper. The combustion air enters the mixing tube through four radial bores and fifteen $45^{\circ}$ slots. The velocity of the combustion air is more than a magnitude lower than that of the atomizing free jet. Therefore, the effect of the former is neglected in the present investigation.

The atomizing air enters the mixing tube through an annulus with $0.8 \mathrm{~mm}$ inner and $1.4 \mathrm{~mm}$ outer diameter. At the axis, the $0.4 \mathrm{~mm}$ diameter fuel jet enters. Due to the velocity difference between the two streams, the atomizing air breaks up the fuel jet into small droplets.

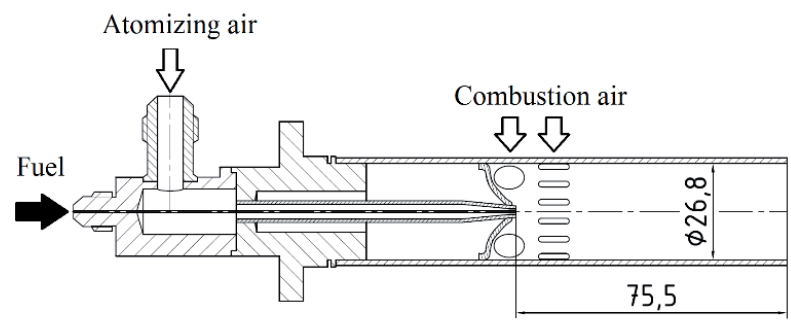

Fig. 1 Schematical drawing of the LPP burner

Two further assumptions are made in order to simplify the calculation method. First, there is one-way coupling between the atomizing and the fuel jet. Second, the droplets are traveling at the axis. Hence, the problem becomes one dimensional. By the mentioned assumptions, the residence time of the spray is certainly underestimated. Therefore, the presented method is conservative. More details about the experiments related to this burner can be found in the literature (see, e.g., $[9,13]$ ).

In order to determine the accurate mass flow rate of the atomizing air at a given atomizing gauge pressure, a measurement was carried out. The configuration consisted a pressure regulator, which was connected to the high-pressure air system of the laboratory, then a variable area flowmeter (3-30 liter/minute measurement range, $4 \%$ accuracy class according to VDI/ VDE 3513), and a pressure transducer (Siemens SITRANS P serie Z, model no.: 7MF1563-5BE00, measurement range: 0-4 bar, absolute). Figure 2 shows the results with a fitted power law curve, including the combined expanded uncertainties. The error bars of the pressure measurement is omitted, due to the high accuracy of the pressure transducer $(0.25 \%$ of full scale, which is $1000 \mathrm{kPa}$ here).

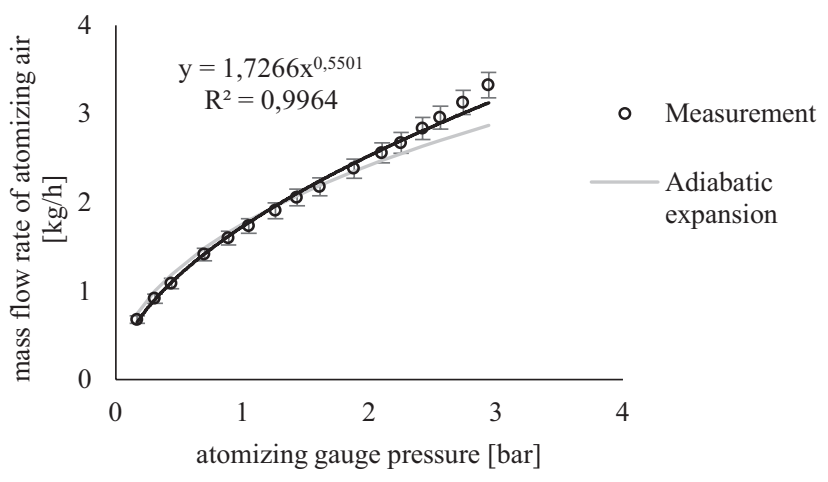

Fig. 2 SMD of different fuel types at various atomizing gauge pressures

Then the obtained results were compared to the adiabatic expansion of the atomizing air. Nonetheless, there is no significant difference between them, the equation of the fitted curve is used for further calculations. The difference in the mass flow rate is observable between the trends above 2 bar atomizing gauge pressure. This phenomenon can be explained by the nonadiabatic process in the reality, i.e., the heat transfer between the environment and the jet increases by the increasing temperature difference between them.

\section{Theoretical background}

In order to characterize a spray, the Sauter Mean Diameter ( $\mathrm{SMD}$ or $\mathrm{D}_{32}$ ) is the most widely used property. Rayleigh was the first, who described the droplet formation from a free liquid jet in 1878 [14]. To date, there is even no analytical solution to determine the SMD for practical atomizers accurately. Therefore, various semi-empirical formulas were developed for specific atomizer types [15]. The widely recognized formula for air blast atomizers was published by Rizk and Lefebvre in 1984 [16]:

$$
\begin{aligned}
S M D & =d_{0}\left[0.48\left(\frac{\sigma}{\rho_{A, 0} U_{R, 0}^{2} d_{L, 0}}\right)^{0.4}\left(1+\frac{1}{A L R}\right)^{0.4}\right. \\
& +0.15\left(\frac{\mu_{L}^{2}}{\sigma_{\rho L, 0} d_{0}}\right)^{0.5}\left(1+\frac{1}{A L R}\right)
\end{aligned}
$$

However, Eq. (1) was developed for $U_{A, 0}$ of 10-120 m/s, utilizing kerosene, gas oil, and blended oils, it was turned out by Phase Doppler Anemometry (PDA) analysis of the investigated 
burner that the predicted SMD fits fairly to the measurement data even out of the original range of availability. The PDA measurement results will be published later on. Consequently, this formula is used as an input for calculating the droplet evaporation.

After the atomizing air exits the annulus, shown in Fig. 1, it forms a free jet. The decay of its velocity along the axis is different from that of a circular free jet. The following formula was suggested by Zawadzki et al. for a similar annulus configuration, which was found to be valid for subsonic conditions [17]:

$$
U_{A}(x)=6 U_{A, 0} d_{a, 0} / x
$$

Due to the constant/x nature of Eq. (2), the velocity characteristics were consequently overridden by $U_{A, 0}$ until the expression became equal to the initial value (i.e. $x=6 d_{A, 0}$ ). However, Eq. (2) was fit to a special measurement configuration, it shows excellent agreement with general free jet theories while the length of the core of a conventional axisymmetric free jet is typically 5-6 $d_{A, 0}[18]$.

In order to simplify the equations of droplet evaporation, the following assumptions has to be made [15]:

1. The droplet is spherical.

2. The fuel is a pure liquid having a well-defined boiling point.

3. Radiation heat transfer is negligible.

4. Lewis number is of unity.

These conditions are fulfilled in the practice, except the case of highly luminous or very low-pressure flames. The former one indicates high soot content, which is the precursor of higher $\mathrm{CO}$ emission than it is allowed by the standards. The latter one is simply not typical in everyday combustion systems.

The lifetime of a droplet can be divided into two stages: the heat-up period, which is followed by the steady state evaporation. During the heat-up phase, significant evaporation can occur, based on the fuel properties. Hence, the droplet is smaller when the steady-state evaporation begins. The sum of the two phases is the total time required for evaporation. According to Driscoll [19], the $D^{2}$ law will be used, while it overestimates the evaporation time. Therefore, the results tend even more to the conservative way.

$$
\begin{gathered}
D_{0}^{2}-D_{h u, e}^{2}=\lambda_{h u} t_{h u} \\
D_{h u, e}^{2}=\lambda_{s t} t_{s t}
\end{gathered}
$$

$\mathrm{D}_{0}$ is assumed to be equal to the previously calculated SMD. Therefore an average-sized droplet will be investigated. The evaporation constant and the heat-up time are:

$$
\begin{gathered}
\lambda_{h u}=8 k_{c} \ln \left(1+B_{M}\right) / c_{p, C} \rho_{L} \\
t_{h u}=\frac{c_{p, L} \rho_{L} c_{p, C} D_{h u, e}^{2}\left(T_{s, s t}-T_{s, 0}\right)}{12 k_{C} \ln \left(1+B_{M}\right) L\left(B_{T} / B_{M}-1\right)}
\end{gathered}
$$

Hence, $D_{h u}$ can be determined by substituting Eqs. (5) and (6) to (3). The only difference from the calculation point of view between the steady-state and heat-up period is $B_{M}$ is equal to $B_{T}$. Therefore, $\lambda_{s t}$ is calculated with Eq. (5) in order to get $t_{s t}$.

Here, the curious reader is redirected to Lefebvre [15] for further details of the theoretical background of evaporation calculation. The material properties of Eqs. (5) and (6) are integral mean values. Otherwise, they are initial values having a 0 subscript. Assuming that the droplets are traveling alone - rather than in a dense cluster with strong cross effects - is a fair estimation of the reality [15].

The chemical structure of the investigated vegetable oils is a glycerin, which connects to three fatty acids. The overall probability of a fatty acid type in their molecule is shown in Table 1. In the second column, the number of carbon atoms and the number of unsaturated bonds are shown. If the probability of a fatty acid in a vegetable oil is about the measurement error, it is marked with 'not relevant' (NR).

However, the weather and the climate have a notable impact on the molecular composition. Therefore, typical ranges were shown in Table 1. Consequently, the physical properties of the crude vegetable oils also vary. Therefore, the authors mainly focus on qualitative rather than a quantitative evaluation of the results.

Table 1 The probability of different fatty acids in the molecular structure of the investigated vegetable oils [20]

\begin{tabular}{lllllll}
\hline Fatty acids & Structure & Rapeseed & Sunflower & Palm & Soybean & Jatropha \\
\hline Lauric & $12: 0$ & NR & $0-0.5$ & $0.13-0.23$ & NR & 0.31 \\
Myristic & $14: 0$ & $<0.1$ & $0-0.2$ & $0.85-0.91$ & $<0.1$ & 0.1 \\
Palmitic & $16: 0$ & $3-4.7$ & $3.5-6.7$ & $36.75-40$ & 11.2 & $13.4-14.2$ \\
Stearic & $18: 0$ & $1-2$ & $1.3-5.9$ & 2.49 & 2.9 & $5.44-7$ \\
Oleic & $18: 1$ & $62.5-65.3$ & $14-43$ & $43-49.8$ & 25.2 & $43.1-45.79$ \\
Linoleic & $18: 2$ & $19.2-22$ & $44-74$ & $11-12.26$ & 55.4 & $32.27-34.4$ \\
Linolenic & $18: 3$ & $8-9$ & $0-0.8$ & $0.1-0.54$ & 5.0 & 0.2 \\
\hline
\end{tabular}


The required physical properties for SMD calculation of the investigated crude vegetable oils of Table 1 at $20^{\circ} \mathrm{C}$ along with the other fuels are shown in Table 2 [20-26].

Table 2 Physical properties of the investigated fuels for SMD calculation

\begin{tabular}{lllll}
\hline Fuel & $\sigma[\mathrm{N} / \mathrm{m}]$ & $\mu^{*} 10^{3}[\mathrm{~kg} / \mathrm{ms}]$ & $\rho\left[\mathrm{kg} / \mathrm{m}^{3}\right]$ & $L H V[\mathrm{MJ} / \mathrm{kg}]$ \\
\hline Ethanol & 0.0227 & 1.2 & 789 & 26.8 \\
n-Heptane & 0.0209 & 0.414 & 684 & 44.6 \\
Diesel & 0.025 & 2.5 & 835 & 43 \\
RME & 0.0314 & 6.7 & 893 & 37.1 \\
Jatropha & 0.031 & 50 & 879 & 38 \\
Palm & 0.0332 & 106 & 890 & 37 \\
Rapeseed & 0.0338 & 70 & 920 & 37 \\
Soybean & 0.0338 & 60 & 920 & 37.8 \\
Sunflower & 0.0337 & 49 & 919 & 37.8 \\
\hline
\end{tabular}

In practical devices, the combustion power demand is given rather than the fuel flow rate. Consequently, SMD calculations were carried out keeping $15 \mathrm{~kW}$ of firing power, which comes from the previous experimental studies $[9,13]$.

Evaporation of diesel oil and n-heptane droplets rely on the extensive data by Lefebvre [15]. The physical properties of ethanol are also well-known. Therefore, the required data is gathered from high-quality web databases [27-30]. Typically, the required properties for evaporation as a function of the temperature of the remaining fuels are quite rare in the literature according to the best knowledge of the authors. Therefore, only rapeseed and soybean oil were investigated from evaporation point of view, using the following data [25,31-35] power law, and Arrhenius.

\section{Results and discussion}

Figure 3 shows the SMD characteristics of the investigated fuels at $20{ }^{\circ} \mathrm{C}$ and under atmospheric pressure. Ethanol is omitted, while its trend is exactly overlapped that of diesel oil. Based on the calculation, three groups can be clearly identified. Palm oil has the highest SMD at all atomization pressures, while it is solid at room temperature and atmospheric pressure, envisaging an outstandingly high viscosity. It is not a surprise that the other crude vegetable oils have similar atomization characteristics, while their chemical structure and atomization properties are quite similar, shown previously in Table 1 and 2. The fossil fuels along with the ethanol and the RME are already proven in our heat engines. Consequently, they show the most favorable atomization characteristics among the investigated fuels.

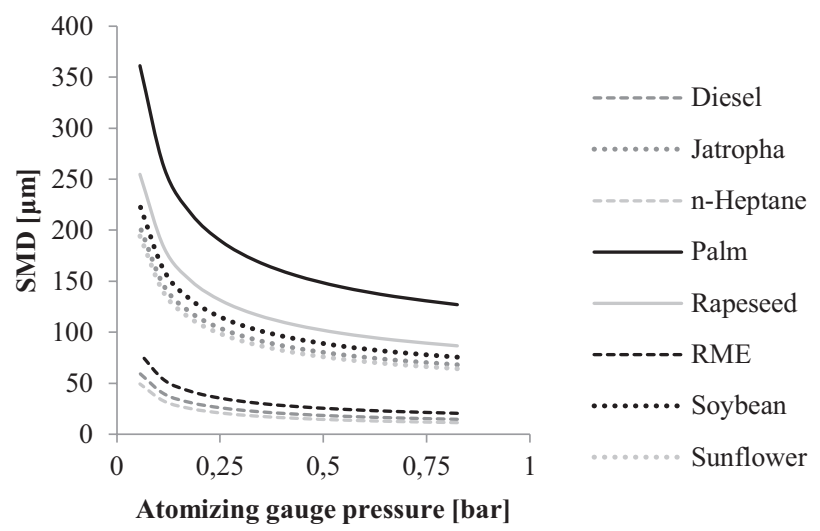

Fig. 3 SMD of different fuel types at various atomizing gauge pressures

Having a low SMD does not necessarily results in complete evaporation in the mixing tube. Volatility is also of importance, which usually grows with the length of the carbon chain. The temperature of combustion air was set to a constant value of $700 \mathrm{~K}$, also based on the previous measurement series $[9,13]$.

Table 3 contains the atomization and evaporation characteristics of the investigated fuels at $700{ }^{\circ} \mathrm{C}$ and atomization gauge pressure of 0.818 bar (critical pressure ratio, hence maximum investigated value), 0.333 bar (between the limits of the investigation by atomizing air exit velocity), and 0.053 bar (minimum investigated value). Hence, the SMD is fully determined for each fuel type. The ratio of the heat-up period to the total time of evaporation $\left(t_{h u}+t_{s t}\right)$ depends only on the material properties in this situation. Consequently, the lower values correspond to the more volatile fuels. The residence time of a single droplet is estimated as $5.39,8.03$, and $20.17 \mathrm{~ms}$, respective to the mentioned three atomization gauge pressures.

Figure 4 shows the ratio of residence time and evaporation time of diesel oil, ethanol, n-heptane, soybean oil, and rapeseed oil in a logarithmic scale.

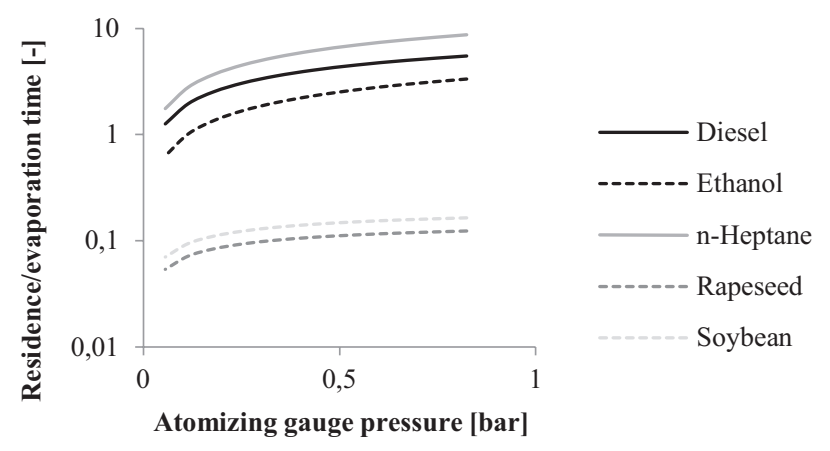

Fig. 4 Ratio of residence and evaporation time for different fuels, $T_{s, 0}=21{ }^{\circ} \mathrm{C}$,

$$
T_{s, s t}=700 \mathrm{~K}
$$


Table 3 Atomization and evaporation characteristics at different gauge pressures and $700 \mathrm{~K}$ combustion air temperature

\begin{tabular}{|c|c|c|c|c|c|}
\hline Fuel & $p_{a t, g}[\mathrm{bar}]$ & $S M D[\mu \mathrm{m}]$ & $t_{h u}[\mathrm{~ms}]$ & $t_{h u}+t_{s t}[\mathrm{~ms}]$ & $t_{h u} / t_{h u}+t_{s t}$ \\
\hline \multirow{3}{*}{ Diesel } & 0.818 & 14.70 & 0.46 & 0.98 & 0.471 \\
\hline & 0.333 & 22.34 & 1.06 & 2.25 & 0.471 \\
\hline & 0.053 & 59.53 & 7.54 & 16.01 & 0.471 \\
\hline \multirow{3}{*}{ Ethanol } & 0.818 & 14.00 & 0.14 & 1.61 & 0.086 \\
\hline & 0.333 & 22.13 & 0.35 & 4.02 & 0.086 \\
\hline & 0.053 & 62.48 & 2.76 & 32.04 & 0.086 \\
\hline \multirow{3}{*}{ n-Heptane } & 0.818 & 10.68 & 0.12 & 0.62 & 0.191 \\
\hline & 0.333 & 16.67 & 0.29 & 1.50 & 0.191 \\
\hline & 0.053 & 46.11 & 2.20 & 11.48 & 0.191 \\
\hline \multirow{3}{*}{ Rapeseed } & 0.818 & 86.68 & 29.75 & 43.46 & 0.684 \\
\hline & 0.333 & 117.16 & 54.35 & 79.40 & 0.684 \\
\hline & 0.053 & 254.70 & 256.84 & 375.25 & 0.684 \\
\hline \multirow{3}{*}{ Soybean } & 0.818 & 75.58 & 19.86 & 32.68 & 0.608 \\
\hline & 0.333 & 102.43 & 36.47 & 60.02 & 0.608 \\
\hline & 0.053 & 224.07 & 174.52 & 287.22 & 0.608 \\
\hline
\end{tabular}

Here, unity means that a fuel droplet requires the $75.5 \mathrm{~mm}$ long mixing tube to evaporate completely. Ratios above one mean that the droplet is fully evaporated before it reaches the burner tip. Diesel oil and n-heptane fulfill this condition at all atomization pressures. However, droplets of ethanol under 0.11 bar atomization gauge pressure, soybean oil, and rapeseed oil are present even at the burner tip. Therefore, utilization of the crude vegetable oils at room temperature can result in incomplete combustion.

To avoid the adverse effect of present droplets at the flame front there are two options. One is to increase the fuel temperature by preheating. Hence, the viscosity drops, and it results in a smaller SMD. Therefore, the evaporation time is also reduced, shown in Fig. 5. At lower temperatures rapeseed oil is less volatile than soybean oil. By increasing the temperature (hence $T_{s, 0}$ increases), the gap between them closes, but it is found to be always present. At $140{ }^{\circ} \mathrm{C}$ droplet temperature, rapeseed and soybean oils catch up to the diesel oil, which is shown for comparison reasons. Consequently, adequate preheating can result in favorable combustion properties of such vegetable oils.

The second method is to increase the combustion air inlet temperature, which can be achieved, e.g., by using an internal heat exchanger in gas turbines. Due to the typical operation parameters, the latter method is limited to small scale units.

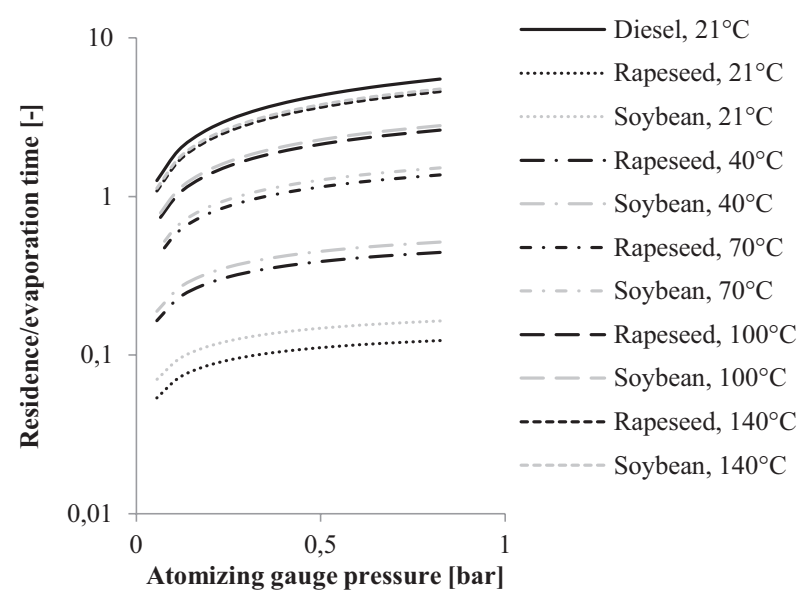

Fig. 5 Ratio of residence and evaporation time for rapeseed and soybean oils with fuel preheating

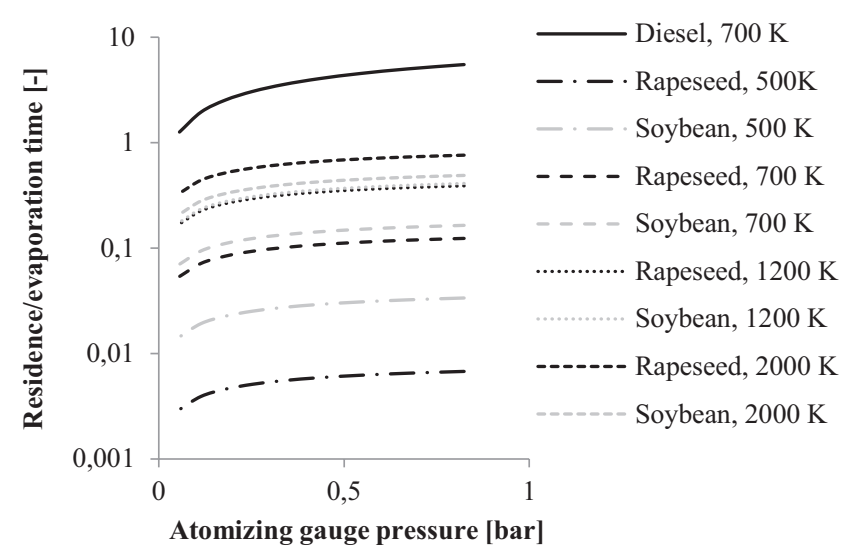

Fig. 6 Ratio of residence and evaporation time for rapeseed and soybean oils with combustion air preheating

Similarly to Fig. 5, there is also a gap between the trends of soybean and rapeseed oil in Fig. 6 which closes by increasing the combustion air temperature. Interestingly, at $1200 \mathrm{~K}$ the trends overlap each other. At $2000 \mathrm{~K}$ the rapeseed oil outperforms the soybean oil. However, combustion air preheating is an effective tool to increase the ratio of residence and evaporation time, but fuel preheating in the range of the current analysis was found to work better. Furthermore, $2000 \mathrm{~K}$ lies $500 \mathrm{~K}$ beyond of the melting point of typical structural steels. Therefore, an advanced cooling system and more expensive materials are required in such environment. In practice, the energy demand of fuel preheating is negligible compared to combustion air preheating. However, fuel temperature of $140{ }^{\circ} \mathrm{C}$ is usually high for plastic fuel pipes, but metal pipes can easily withstand that environment. 


\section{Conclusions}

An analytical investigation was carried out on the atomization and evaporation characteristics of different liquid fossil (n-heptane, diesel oil) and renewable fuels (ethanol, rapeseed methyl ester (RME), and the following crude vegetable oils: palm, rapeseed, soybean, and sunflower). A lean premixed prevaporized (LPP) atmospheric burner equipped with an air blast atomizer was the calculation domain. The following practical aspects of the operation were considered: keeping the firing power at constant (i.e. $15 \mathrm{~kW}$ in this case), modifying the atomization gauge pressure, preheating the low volatile fuels, and increasing the temperature of the combustion air in the mixing tube. The following conclusions were derived:

1. Air blast atomization of RME, diesel oil, n-heptane, and ethanol resulted in similar Sauter mean diameters (SMDs). The crude vegetable oils are separate from them, showing much larger average droplet sizes, compared to the above-mentioned fuels. Due to the similar molecular structure of the vegetable oils, their atomization characteristics are very close to each other, except the highly viscous palm oil. Therefore, it showed the largest SMD among all fuels.

2. The ratio of residence to evaporation time showed that by utilizing crude vegetable oils (i.e. rapeseed and soybean oils here), at least, one magnitude longer residence time would be necessary compared to the trends of fossil fuels and ethanol. Therefore, using vegetable oils as fuel at room temperature can lead to incomplete combustion.

3. The higher fuel temperature results in smaller droplets, hence, rapeseed and soybean oil performs similarly at $140{ }^{\circ} \mathrm{C}$ than diesel oil at $2{ }^{\circ} \mathrm{C}$. However, preheating the combustion air also increases the ratio of residence and evaporation time, the environment of $2000 \mathrm{~K}$ is still not enough for complete evaporation of rapeseed and soybean oils in the present configuration.

Application of the presented calculation method can give a fair evaporation estimation for combustion engineers to design our current heat engines to run on even crude vegetable oils.

\section{Acknowledgement}

This research was supported by BUTE Department of Energy Engineering relating to the grant TÁMOP4.2.2.B-10/1-2010-0009.

\section{Nomenclature}

$\begin{array}{lll}A L R & {[-]} & \text { air-to-liquid mass ratio } \\ B_{M} & {[-]} & \text { mass transfer number } \\ B_{T} & {[-]} & \text { thermal transfer number } \\ c_{p} & {[\mathrm{~J} / \mathrm{kgK}]} & \text { specific heat at constant pressure } \\ d & {[\mathrm{~m}]} & \text { hydraulic diameter of a free jet } \\ D & {[\mathrm{~m}]} & \text { diameter of a droplet }\end{array}$

\section{Subscripts}

0

A

C

e

$L$

hu

$R$

$s$

st

\section{References}

[1] Correa, S. M. "Power generation and aeropropulsion gas turbines: From combustion science to combustion technology." Symposium on Combustion. 27(2), pp. 1793-1807. 1998.

DOI: 10.1016/S0082-0784(98)80021-0

[2] Chen, H-G., Zhang, Y-H. P. "New biorefineries and sustainable agriculture: Increased food, biofuels, and ecosystem security." Renewable and Sustainable Energy Reviews. 47, pp. 117-132. 2015.

DOI: 10.1016/j.rser.2015.02.048

[3] Kourmatzis, A., Pham, P. X., Masri, A. R. "Air assisted atomization and spray density characterization of ethanol and a range of biodiesels." Fuel. 108, pp. 758-770. 2013. DOI: 10.1016/j.fuel.2013.01.069

[4] Chigier, N. A. "The atomization and burning of liquid fuel sprays." Progress in Energy and Combustion Science. 2(2), pp. 97-114. 1976.

DOI: 10.1016/0360-1285(76)90019-8

[5] Ghorbani, A., Bazooyar, B. "Optimization of the combustion of SOME (soybean oil methyl ester), B5, B10, B20 and petrodiesel in a semi industrial boiler." Energy. 44(1), pp. 217-227. 2012. DOI: $10.1016 /$ j.energy.2012.06.035

[6] Lefebvre, A. H., Miller, D. "The Development of an Air Blast Atomizer for Gas Turbine Application. CoA. Report Aero No. 193 June." 1966.

[7] Zeoli, N., Gu, S. "Computational validation of an isentropic plug nozzle design for gas atomisation." Computational Materials Science. 42(2), pp. 245-258. 2008. DOI: 10.1016/j.commatsci.2007.07.013

[8] Hede, P. D., Bach, P., Jensen, A. D. "Two-fluid spray atomisation and pneumatic nozzles for fluid bed coating/agglomeration purposes: A review." Chemical Engineering Science. 63(14), pp. 3821-3842. 2008. DOI: 10.1016/j.ces.2008.04.014

[9] Kun-Balog, A., Sztankó, K. "Reduction of pollutant emissions from a rapeseed oil fired micro gas turbine burner." Fuel Processing Technology. 134, pp. 352-359. 2015. DOI: 10.1016/j.fuproc.2015.02.017 
[10] Lefebvre, A., Ballal, D. R. "Gas turbine combustion." 3rd edition. Boca Raton: CRC Press. 2010.

[11] Correa, S. M. "A Review of NOx Formation Under Gas-Turbine Combustion Conditions." Combustion Science and Technology. 87(1-6), pp. 329-362. 1993. DOI: 10.1080/00102209208947221

[12] Huang, Y., Yang, V. "Dynamics and stability of lean-premixed swirl-stabilized combustion." Progress in Energy and Combustion Science. 35(4), pp. 293-364. 2009. DOI: 10.1016/j.pecs.2009.01.002

[13] Józsa, V., Kun-Balog, A. "Spectroscopic analysis of crude rapeseed oil flame." Fuel Processing Technology. 139, pp. 6-11. 2015. DOI: 10.1016/j.fuproc.2015.08.011

[14] Rayleigh, L. "On The Instability Of Jets." Proceedings of the London Mathematical Society. S1-10(1), pp. 4-13. 1878.

DOI: $10.1112 / \mathrm{plms} / \mathrm{s} 1-10.1 .4$

[15] Lefebvre, A. H. "Atomization and Sprays." Hemisphere Publishing Corporation. 1989.

[16] Rizk, N. K., Lefebvre, A. H. "Spray Characteristics of Plain-Jet Airblast Atomizers." Journal of Engineering for Gas Turbines and Power. 106(3), pp. 634-638. 1984. DOI: 10.1115/1.3239617

[17] Zawadzki, L., Cichoń, J., Jarzębowski, J., Kapusta, H. "Determination of the Air Velocity in the Free Stream Flowing out of a Cylindrical and Two-Gap Skewed Jet (Dual Slot Die)." FIBRES \& TEXTILES in Eastern Europe. 18 (5). pp. 39-43. 2010.

[18] Lajos, T. Fundamentals of fluid mechanics. 4th ed. Budapest. 2008. (in Hungarian)

[19] Driscoll, J. F. "Premixed Turbulent Combustion - Regimes of Thickened and Distributed Reactions." In: D’Anna, A., Selcuk, N., Bereta, F. M. M. (eds.): Electron. Proceedings of the 9th Mediterranean combustion Symposium, Rhodes, Greece, 7-11 June: 2015.

[20] Melo-Espinosa, E. A., Sánchez-Borroto, Y., Errasti, M., Piloto-Rodríguez, R., Sierens, R., Roger-Riba, J., Christopher-Hansen, A. "Surface Tension Prediction of Vegetable Oils Using Artificial Neural Networks and Multiple Linear Regression." Energy Procedia. 57, pp. 886-895. 2014. DOI: 10.1016/j.egypro.2014.10.298

[21] Vauhkonen, V., Lauhanen, R., Ventelä, S., Suojaranta, J., Pasila, A., Kuokkanen, T., Prokkola, H., Syvajarvi, S. "The phytotoxic effects and biodegradability of stored rapeseed oil and rapeseed oil methyl ester." Agricultural and Food Science. 20(2), pp. 131-42. 2011. DOI: $10.2137 / 145960611797215673$

[22] Gis, W. "Properties of the Rapeseed Oil Methyl Esters and Comparing Them With the Diesel Oil Properties." Journal of KONES Powertrain and Transport. 18(4), 2011. URL: http://ilot.edu.pl/ kones/2011/4_2011/2011_gis_zoltowski-bochenska_properties.pdf
[23] Raja, S., Smart, D., Lee, C. "Biodiesel production from jatropha oil and its characterization." Research Journal of Chemical Sciences. 1(1), pp. 81-87. 2011. URL: http://www.isca.in/rjcse/Archives/vol1/13.pdf

[24] Patzek, T. W. "A First Law Thermodynamic Analysis of Biodiesel Production From Soybean." Bulletin of Science, Technology \& Society. 29(3), pp. 194-204. 2009. DOI: 10.1177/0270467609334022

[25] Fasina, O. O., Colley, Z. "Viscosity and Specific Heat of Vegetable Oils as a Function of Temperature: $35^{\circ} \mathrm{C}$ to $180^{\circ} \mathrm{C}$." International Journal of Food Properties. 11(4), pp. 738-746. 2008.

DOI: $10.1080 / 10942910701586273$

[26] Tesfa, B., Gu, F., Mishra, R., Ball, A. D. "LHV predication models and LHV effect on the performance of CI engine running with biodiesel blends." Energy Conversion and Management. 71, pp. 217-226. 2013. DOI: 10.1016/j.enconman.2013.04.005

[27] National Institute of Standards and Technology. [Online]. Available from: www.nist.gov [Accessed: 9th September 2015]

[28] Dortmund Data Bank (DDB). [Online]. Available from: www.ddbst.com [Accessed: 9th September 2015]

[29] Thermal-Fluids Central. [Online]. Available from:. www.thermalfluidscentral.org [Accessed: 9th September 2015]

[30] Engineers Edge. [Online]. Available from: www.engineersedge.com [Accessed: 9th September 2015]

[31] Parrilla, J., Cortés, C. "Modelling of droplet burning for rapeseed oil as liquid fuel." Proceedings of the International Conference on Renewable Energies and Power Quality. Palma de Mallorca, 5-7 April 2006. URL: http://www.icrepq.com/icrepq07/221-parrilla.pdf

[32] Esteban, B., Riba, J. R., Baquero, G., Rius, A., Puig, R. "Temperature dependence of density and viscosity of vegetable oils." Biomass and Bioenergy. 42, pp. 164-171. 2012. DOI: 10.1016/j.biombioe.2012.03.007

[33] Murata, S., Tanaka, F. "Measurements of Vapor Pressure of a Series of Edible Oils." Nippon Shokuhin Kogyo Gakkaishi. 39(4), pp. 333-338. 1992. DOI: $10.3136 /$ nskkk1962.39.333

[34] Vyacheslav, V. K. "Handbook on Dielectric and Thermal Properties of Microwaveable Materials." Artech House Microwave Library. 2012.

[35] Ndiaye, P. M., Lanza, M., Tavares, F. W., Dariva, C., Oliveira, D., Vladimir, O. J. "Phase behavior of olive and soybean oils in compressed propane and n-butane." Brazilian Journal of Chemical Engineering. 23(3), pp. 405-415. 2006. DOI: 10.1590/s0104-66322006000300014 